\title{
Sustainable Navigation Rhine Delta Branches, a Reconnaissance of Strategies
}

\author{
G.J. Akkerman \& M.A. van Heereveld \\ Royal Haskoning Consultants, Architects and Engineers, Nijmegen, Netherlands \\ H.J. Barneveld \\ HKVConsultants, Lelystad, Netherlands
}

R.J. Smedes

Ministry of Transport, Public Works and Water Management, East Regional Directorate, Arnhem, Netherlands

ABSTRACT: To facilitate sustainable navigation for the Rhine Delta branches, extensive research is being carried out in the Netherlands. A first step of this research is a reconnaissance of potentially feasible fairway improvement strategies. This reconnaissance comprises a wide range of measures and their indicative hydraulic and morphological effects, against the background of ongoing degradation of the main channels and the adverse effects of climate change. Future intensification of fairway traffic calls for enlargement of the fairway channel. With the current maintenance strategy, dredging frequency and volumes will also strongly increase. Hence, apart from other dredging strategies, structural measures are considered so as to reduce the increasing maintenance dredging effort. The reconnaissance of potential measures includes efficacy, practical feasibility, maintenance efforts and economy. Attention is also paid on sustainability. The present paper presents a review of problems, general results and illustrates some potentially feasible measures .

\section{BACKGROUND}

Navigation at the largest rivers in The Netherlands, the Rhine / Waal system as a part of the Rhine Delta, see Figure 1, has been important for inland transport for some centuries. In the last decades, this importance is even strongly increasing due to further intensification of fairway traffic between the main ports of Rotterdam and Duisburg (Germany) in the years to come. A further growth of navigation commodities in the near future is to be expected. One of the short-term objectives of the project 'Sustainable Fairway Rhine Delta' is the enlargement of the present navigation channel dimensions from $150 \mathrm{~m}$ (width) and 2,50 m (depth) to $170 \mathrm{~m}$ (width) and 2,70 m (depth) at Agreed Low Discharge and the accompanying Lowest Available Depth (exceeded in 95\% of time).

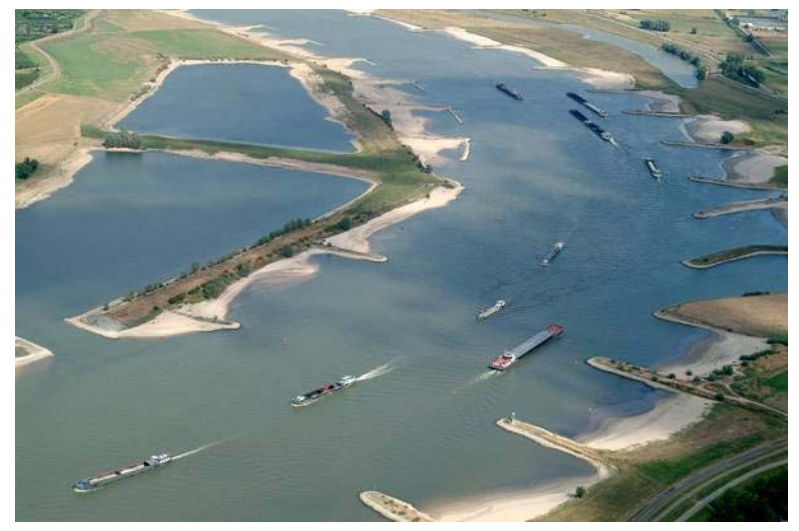

Figure 1. Impression of navigation on the Waal river at low flow
At the same time, ongoing degradation of the main channels and effects of climate change poses upcoming threats to navigability.

The degradation rate in the upper part of the Waal River amounted to 1 to $1.5 \mathrm{~m}$ in the last 50 years, although degradation seems to slow down more recently. Due to this bed degradation, problems may arise such as the access to locks, to mooring facilities and to river harbour entrances. In addition, the groynes near the banks are becoming over-exposed during high flows and underexposed during low flows and groundwater levels drop. On the longer term, even the filled up stabilization of sharp outer bends (fixed layers), in order to maintain sufficient width, may form a barrier on the river bed, limiting the water depth during low flow conditions.

Ongoing bed degradation in the Rhine / Waal system is, amongst others, a long term consequence of river training works and flood plain occupation over the last century and a shortage of sediment influx from across the German border. The latter is due to normalisation works and subsidence of the riverbed in the upstream mining areas. This is not a problem that is exclusive to the Rhine Delta rivers: at present, many European rivers suffer severe bed degradation due to the same causes.

The bed degradation on the Waal is illustrated in Figure 2. It is clearly visible how the fixed layer Nijmegen has become more pronounced in time. 


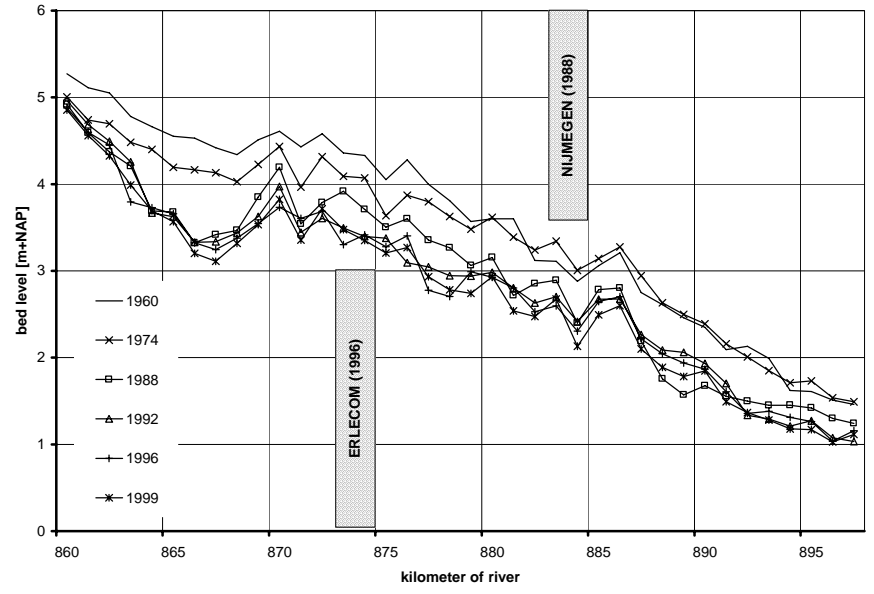

Figure 2. Degradation of part of the main channel of the Waal (longitudinal profile)

Present dredging estimates amount to 300,000 to $500,000 \mathrm{~m}^{3}$ (measured in profile) on a yearly basis. The exact amount varies strongly over the years, mainly due to the variation in annual (peak) discharges. Recent figures are not known accurately, due to the recently negotiated performance contract with the dredging company. The planned enlargement of the navigation channel dimensions may increase the yearly maintenance dredging to about $1,000,000 \mathrm{~m}^{3}$ as an order of magnitude, if other measures would not be implemented.

The last decade, the dredging strategy has been changed so as to mitigate the ongoing degradation: nowadays the dredged material is not removed from the river system anymore, but is dumped upstream at deeper locations at a minimum distance from the dredging site $(1.5 \mathrm{~km})$. In this way the dredged material is 'circulated'. Although less effective from a dredging point-of-view, it is a more sustainable methodology since it contributes significantly to mitigating the degradation.

\section{RESEARCH OBJECTIVES}

The present research focuses on an inventory of potential measures that may contribute to improvement of navigation and, at the same time, add to the sustainable development of the river system. An important item for sustainability is reduction of the degradation trend.

The inventory of measures has been based on the outcome of workshops with experts from different disciplines.

In order to elaborate the potential measures to a practical level, the measures have been detailed to a level of functional design. This allowed also providing a rough estimate of the costs involved. Different measures may have a total different distribution of costs during their life cycle: hence, the net present value (NPV) over a 50 years period has been assessed, including maintenance and intermediate reconstruction (if required). The research is to provide directions for further elaboration of sustainable fairway improvement measures and combinations thereof in a subsequent step.

\section{RESEARCH METHOD}

The working methodology for this research was as follows. At first, a brief analysis was made of the present and future major navigation bottlenecks and the present main measure to maintain sufficient depth and width: maintenance dredging. Figures 3 and 4 illustrate some major bottlenecks on the Waal River.

Navigation bottlenecks can be grouped into two types:

1) Structural bottlenecks which mainly occur in sharp bends and which sustain after high flows recede. The position of these bottlenecks is rather stable. Because of the vast extent of the dredging activities required to maintain sufficient width and depth, this dredging is denoted 'profile dredging', see Figure 3.

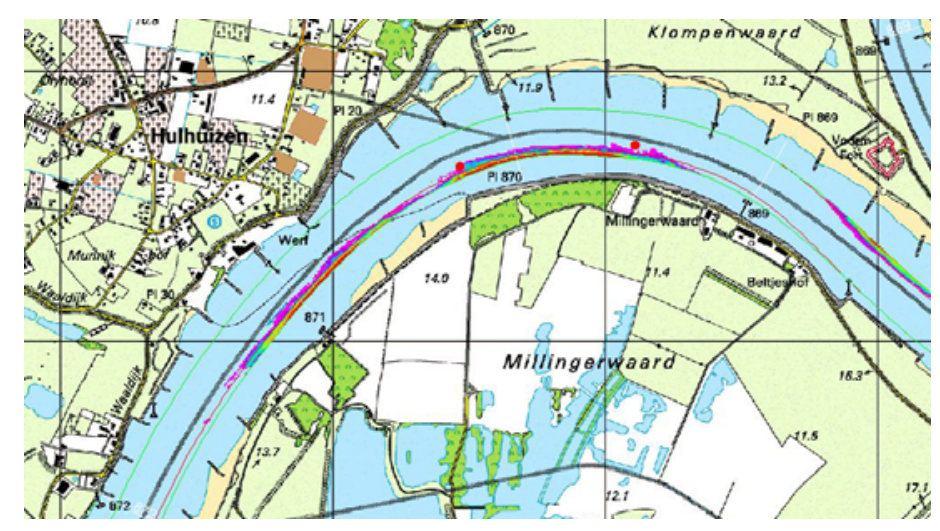

Figure3. Profile dredging locations near sharp bend in the Waal River (coloured bands)

2) Bottlenecks which occur during floods, as well as during low and medium flows on a more erratic basis, due to e.g. retarded scour and large bed forms (sand waves). Dredging these local shoals is dispersed and is denoted 'occasional dredging'.

While the first type can be checked quite well after the floods recede, the second type has to be monitored on a (nearly) day-to-day basis, see Figure 4.

Next a framework for analysis of potential improvement measures was drawn up (see also [2] and [3]). 


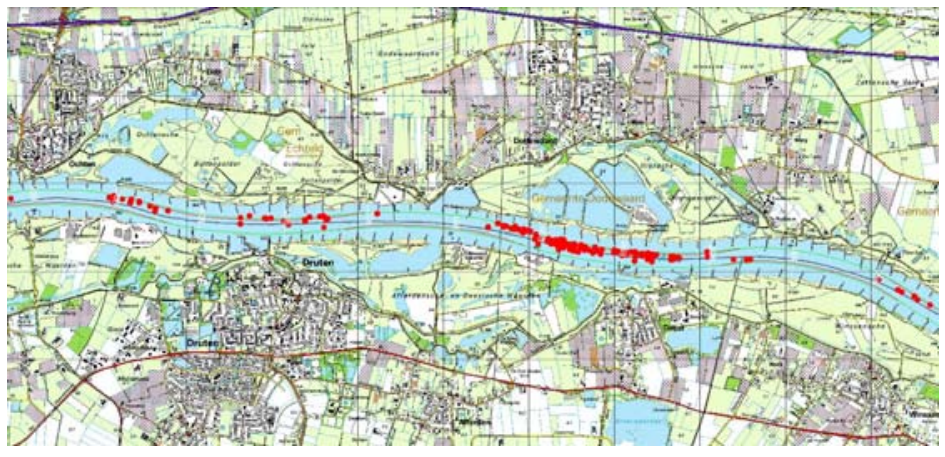

Figure 4. Occasional dredging locations on the Waal river (red dots)

The potential efficacy was assessed on the basis of engineering judgement, within a team of nautical and morphological experts.

As regards the impacts a distinction was made between: impacts on flood levels, change of the discharge distribution at the bifurcation points and interaction with other planned river measures.

Sustainable issues related to the effect on bed degradation, adaptability (=preservation of functionality) in case of further climate change, maintenance and navigation hindrance.

The practical feasibility addresses the practical workability to realize the measure.

Risk and uncertainties, other than stemming from the realization, relate to e.g. the probability of failure during the lifetime, uncertainties on efficacy, adverse impacts and sustainability.

A rough cost assessment was carried out to explore the economical feasibility.

It should be remarked that the measures were judged separately: combinations of measures were not explored yet in this phase of the research.

\section{TYPES OF MEASURES}

Two groups of measures have been considered:

1) Sediment management measures, e.g. dredging of shoals, levelling of scour holes and sediment nourishment;

2) River training measures, e.g. application of bed groynes or fixed layers, adaptation of groynes and roughness elements in inner bends.

Some twenty preliminary concepts of individual measures have been identified and explored in the present reconnaissance study. These measures have been analyzed against the background of the aforementioned framework for analysis.

Some typical measures are indicated hereafter:
Sediment management measures

- Alternative dredging strategy with dumping a part of the dredged material farther upstream to compensate for the sediment transport deficit upstream;

- Filling of sharp outer bends and reduction of transport capacity by applying 'Smart Soils' technology;

- Dredging of inner bends and nourishment of external coarse material in outer bends, see Figure 5;

- Intensification of the stirring action of ships sailing close to shallows;

- Suppletion of a thin semi-stable upper layer to control the bed degradation;

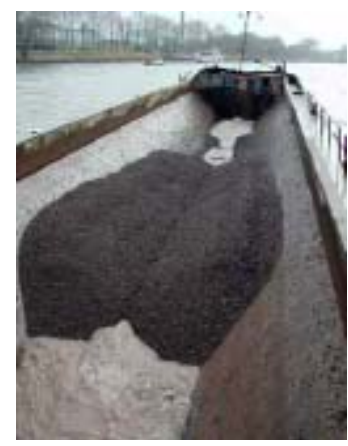

Figure 5: Example of nourishment of external bed material

\section{Structural measures}

- Continuation of the proven methodology of applying fixed layers in sharp outer bends;

- Filling up of scour holes near groynes ('flames') and scour holes downstream of present fixed layers, see Figure 6;

- Continuous stable layer along the whole Rhine / Waal river system;

- Bank alignment measures: a 'flow guidance dam' to close-off groyne sections in inner bends at low flows; a flow guidance structure for groyne heads; a 'turbulence dam' to promote erosion in the inner bends.

Some of these measures are proven technology, others however are highly innovative.

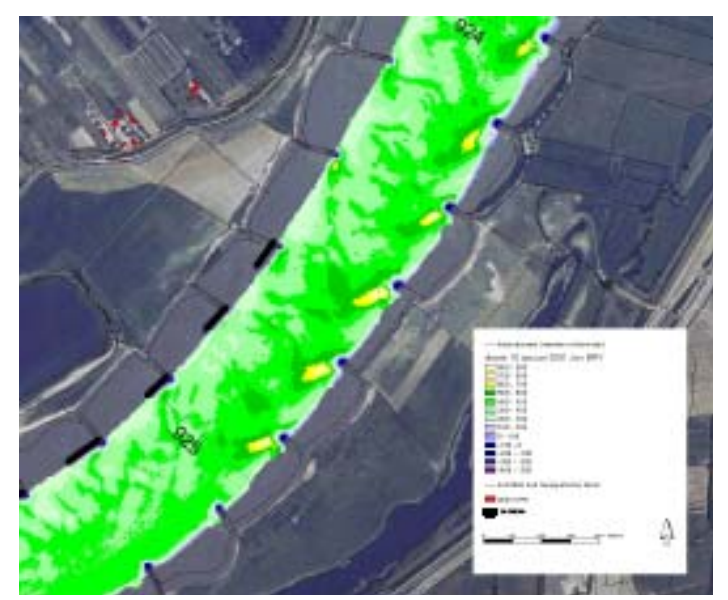

Figure 6: Typical erosion pattern near groynes 


\section{GENERAL FINDINGS}

The current dredging strategy would lead to high efforts and costs for maintaining the enlarged navigation channel in the new situation. The net present value of these activities could be well over $€ 200 \mathrm{M}$. Moreover, hindrance to navigation will be significant. The additional costs for the alternative dredging strategy with dumping of dredged material farther upstream will hardly increase this cost figure but appears to be much more sustainable.

The efficacy of other large-scale sediment management measures, such the as suppletion of a thin semi-stable upper layer, seems to be highly uncertain. At the same time, the savings on the anticipated dredging is not known as well. Other measures, e.g. the deployment of vessels to increase the stirring up action are far beyond practical application. Local measures, i.e. nourishment of coarse (semi-stable) materials in outer bends may be feasible and economical: the net present value for two major bends at the Waal indicate a cost figure of around $€ 20 \mathrm{M}$.

The most efficient measures may still be of the structural type, especially when applied locally in bends. These measures may contribute significantly to the reduction of maintenance dredging. Other promising measures are various bank alignment measures. Hereafter, some of these will be highlighted. The efficacy of filling up present scour holes is uncertain, although this measure may contribute well to reducing 'occasional dredging' in an economical way: the net present cost is nearly $€ 20$ at the major occasional dredging sites of the Waal.

Sustainability of the structural measures is especially positive in terms of durability and low cost of maintenance. However, they do not actively mitigate bed degradation. Therefore, structural measures should be combined with sediment management measures, e.g. the alternative dredging option, supported by nourishment with external coarse bed material.

\section{ILLUSTRATION OF TWO PROMISING BANK ALIGNMENT MEASURES}

The study indicates a number of potentially feasible measures. For illustration purposes, two concepts deemed feasible are described hereafter in more detail.

\subsection{Flow guidance dam}

The flow guidance dam is a dam that is installed in front of the present groynes, see Figures 7 and 8, and serves different purposes:

- Additional resistance at low flows, so as to increase low water levels;

- Reduction of the irregular riverbed patterns in the vicinity of groynes;

- Shelter to the groyne beach section so as to promote environmental conditions.

To avoid adverse effects on flood water levels, the adjoining groynes may need to be removed partly, e.g. by lowering of the crest level.

It is anticipated that this type of flow guidance will give significant savings on the quantity of profile dredging.

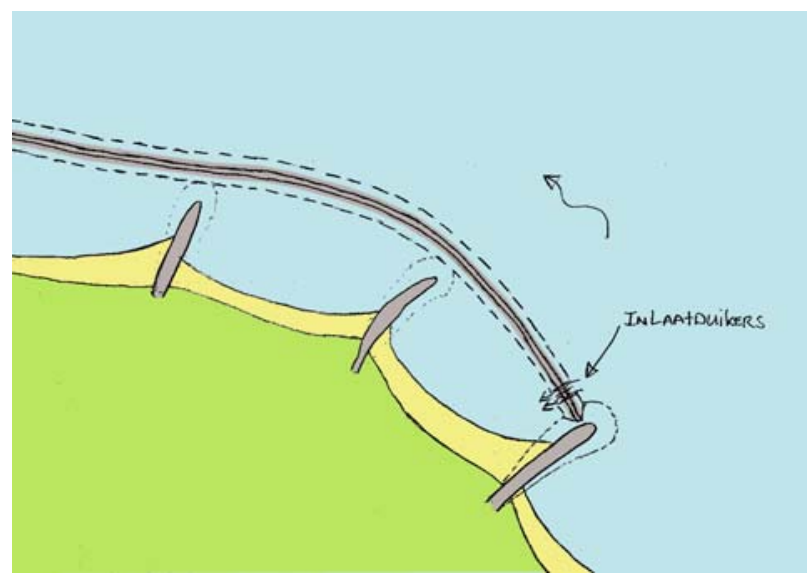

Figure 7 : Top view of the flow guidance dam (upstream section)

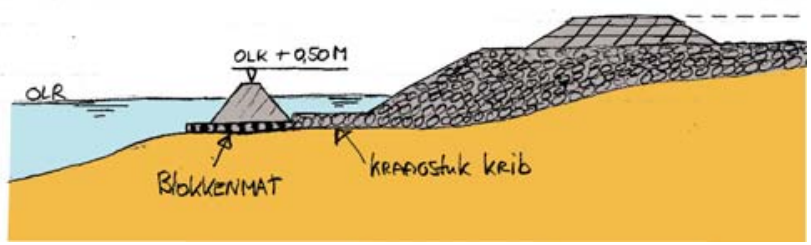

Figure 8: Sketch of the flow guidance dam near a groyne

The anticipated costs (NPV) of this guidance dam are relatively modest: $€ 2.5 \mathrm{M}$ per inner bend of $2 \mathrm{~km}$ length.

\subsection{Flow guidance structure near groyne heads}

This structure, as shown in Figure 9, is meant to guide the flow more smoothly during low flows in inner bends and, at the same time, provide additional resistance to increase low water levels (these functions do compare with the flow guidance dam). 


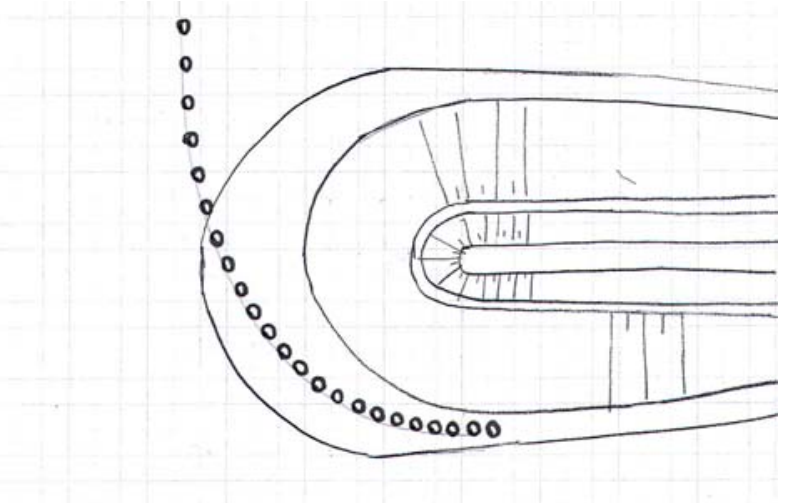

Figure 9 : Top view of the 'spoiler' near a groyne head

(C) Royal Haskoning

To promote a more regular flow pattern near the groyne head, the structure consists of separate poles. The poles introduce small-scale turbulence that disturbs the irregular flow separation around the groyne head and thus impose a 'spoiler' action. The height of the poles will be modest: the top level of the poles may go down from groyne level to around Least Available Depth $+0.5 \mathrm{~m}$ at the downstream end. It is likely that adverse impacts on flood water levels can be avoided.

The anticipated costs of this concept (NPV) are around $€ 5 \mathrm{M}$ for two major sharp bends in the Waal River.

\section{CONCLUSIONS}

The present study points out that adaptation of current practices on maintaining and extension of the nautical profile may be needed for safeguarding sustainable and economical solutions in the future. New dredging strategies, nourishment of external (coarse) bed material and innovative bank alignment measures can contribute to reduce future maintenance dredging.

Predicting maintenance dredging for future scenario's was proven to be complex and uncertain. Further study is needed.

The potential measures need further detailing and in-depth morphological and hydraulic research of their adequacy in reducing maintenance dredging. Such research may comprise field pilots, scale model investigations, desk studies and mathematical model studies. In addition, lessons learned from field pilots carried out in the German part of the Rhine River should be incorporated.

\section{REFERENCES}

[1] Akkerman, G.J., M.A. van Heereveld, et.al (2004): Groyne optimisation and river hydrodynamics, $2^{\text {nd }}$ International Conference on Fluvial Hydraulics, Riverflow2004, Jume 2004, Napoli, Italy.

[2] Havinga H.H. (2005): Sustainable waterways within the context of navigation and flood management, $3^{\text {rd }}$ International Symposium on Flood Defence, 25-27 May 2005, Nijmegen, the Netherlands.

[3] Havinga H.H. (2006): Sustainable waterways within the context of navigation and flood management, $31^{\text {st }}$ PIANC Congress, May 14 - 18, 2006, Estoril, Portugal.

[4] Van der Wal, M., G.J. Akkerman, J.M.T. Stam (2005): Multifunctional river groynes: Providing nautical depth and mitigation of flood levels, 3rd International Symposium on Flood Defence, May 2005, Nijmegen, the Netherlands. 